\title{
A Clinical Comparative Study of Dexmedetomidine with Fentanyl as an Adjuvant to Intrathecal Hyperbaric Bupivacaine for Vaginal Hysterectomy
}

\author{
Yogesh Kumar Manik ${ }^{1}$, Navab Singh² ${ }^{2}$ Vedprakash ${ }^{3}$, Vipin Dhama ${ }^{4}$, Subhash ${ }^{5}$
}

\begin{abstract}
${ }^{1}$ Department of Anaesthesiology, LLRM Medical College, Meerut, Uttar Pradesh, India. ${ }^{2}$ Department of Anaesthesiology, LLRM Medical College, Meerut, Uttar Pradesh, India. ${ }^{3}$ Department of Anaesthesiology, LLRM Medical College, Meerut, Uttar Pradesh, India. ${ }^{4}$ Department of Anaesthesiology, LLRM Medical College, Meerut, Uttar Pradesh, India. ${ }^{5}$ Department of Anaesthesiology, LLRM Medical College, Meerut, Uttar Pradesh, India.
\end{abstract}

\section{ABSTRACT}

\section{BACKGROUND}

Currently only few local anaesthetics are used for intrathecal administration, like bupivacaine, lignocaine, ropivacaine and tetracaine. Opioid analogues have been used as additive in spinal anaesthesia to improve the onset of action, to prolong the duration of block and to improve the quality of intraoperative and postoperative analgesia. Fentanyl is a partial agonist on $\mu$-opioid receptors and Dexmedetomidine is a $\alpha 2$-agonist. Intrathecal dexmedetomidine when combined with spinal bupivacaine prolongs the sensory block by depressing the release of C-fibers transmitters and by hyperpolarization of post-synaptic dorsal horn neurons. ${ }^{1} \mathrm{We}$ compared the effects of adding Dexmedetomidine and Fentanyl as an adjuvant to intrathecal hyperbaric bupivacaine for vaginal hysterectomy.

\section{METHODS}

A total of 100 patients of age 35 to 65 yrs. of body mass index (BMI) within normal range (18.5 to $24.9 \mathrm{Kg} / \mathrm{m}^{2}$ ) posted for vaginal hysterectomy were divided into two equal groups (Group 1 and 2) in a prospective, randomized, double-blind fashion. In Group $1(\mathrm{n}=50),(2.5 \mathrm{ml})$ Hyperbaric Bupivacaine $+(0.5 \mathrm{ml})$ Dexmedetomidine $(5$ $\mathrm{mcg})$ and in Group $2(\mathrm{n}=50)$ (2.5 ml) Hyperbaric Bupivacaine $+(0.5 \mathrm{ml})$ Fentanyl $(25 \mathrm{mcg}$ ) were used. Total volume injected intrathecally was $3.0 \mathrm{ml}$. We observed the effect on onset of sensory and motor blockade, maximum level of sensory and motor blockade, haemodynamic effects during intraoperative period (for $120 \mathrm{~min}$ ), effect on overall duration and quality of analgesia during postoperative period using VAS score and any side effects.

\section{RESULTS}

We observed that mean time to achieve sensory block and motor block/ Bromage-3 was shorter in dexmedetomidine group. There was no statistically significant difference for the onset of sensory and motor block in dexmedetomidine and fentanyl group ( $p$ value $>0.05$ ). The sensory and motor block were more prolonged in dexmedetomidine group than fentanyl group showing significant difference among the two groups ( $p$ value $<0.001$ ). Overall duration of analgesia was significantly longer in dexmedetomidine group than fentanyl group showing significant difference among the two groups ( $p$ value $<0.001$ ).

\section{CONCLUSIONS}

In our opinion adding Dexmedetomidine $5 \mathrm{mcg}$ to Bupivacaine $12.5 \mathrm{mg}$ not only provides rapid onset, profound analgesia with good relaxation for surgery but also prolongs the duration of sensory and motor blockade. The overall effect and duration are superior to addition of $25 \mathrm{mcg}$ of Fentanyl.

\section{KEY WORDS}

Intrathecal, Adjuvants, Fentanyl, Dexmedetomidine, Vaginal Hysterectomy
Corresponding Author: Dr. Yogesh Kumar Manik, Associate Professor, Department of Anaesthesiology, LLRM Medical College, Meerut, Uttar Pradesh, India

E-mail:dr.yogeshkmanik@gmail.com

DOI: 10.14260/jemds/2020/307

Financial or Other Competing Interests: None.

How to Cite This Article:

Manik YK, Singh N, Vedprakash, et al. A clinical comparative study of dexmedetomidine with fentanyl as an adjuvant to intrathecal hyperbaric bupivacaine for vaginal hysterectomy. J. Evolution Med. Dent. Sci. 2020;9(17): 1405-1411, DOI:
Submission 04-03-2020, Peer Review 15-04-2020, Acceptance 22-04-2020, Published 27-04-2020. 


\section{BACKGROUND}

Spinal anaesthesia is a type of regional anaesthesia technique and has got many advantages like, rapid onset, easy to perform without risk of local anaesthetic toxicity. Regional anaesthesia was a term first used by Cushing ${ }^{2}$ in 1901 to describe pain relief by nerve block. Lumbar puncture standardized as a simple clinical procedure by Quincke ${ }^{3}$ of Kiel in Germany in 1891. Bier ${ }^{4}$ of Kiel in Germany gave the first intrathecal anaesthesia in 1898.

At that time muscle relaxants were not introduced and spinal anaesthesia produced profound muscle relaxation, facilitating surgical exposure. It also reduces the incidence of pulmonary embolism and venous thromboembolism ${ }^{5}$. It is used successfully in so many surgical procedures, especially in lower abdominal surgery. Currently only few local anaesthetics are used for intrathecal administration like bupivacaine lignocaine, ropivacaine and tetracaine .Lignocaine for spinal anaesthesia has been used worldwide, some caution of its use in light of the phenomenon of transient neurological symptoms ${ }^{6}$ and cauda equina syndrome (especially when continuous spinal anaesthesia is used) ${ }^{7}$. The bupivacaine was synthesized in Sweden by Ekenstams in 1957 and used clinically by Telivuo in 1963. A $0.25 \%$ and $0.5 \%$ solution used intrathecally and epidurally produces adequate anaesthesia and analgesia. In intrathecal route, heavy bupivacaine is used. Bupivacaine is not associated with any such neurological complications. Its onset is slow (in comparison to others.), but have a prolonged duration of blockade (90-120 min.).

Various additive drugs have been tried with bupivacaine to look for the improvement in the quality and extending the duration of blockade like vasoconstrictors, opioid analogues (Singh H Yang et al ${ }^{7}$ 1995, Jaishribogra et al ${ }^{8}$ 2005, BN Biswas et al. ${ }^{9}$ 2002.), neostigmine, benzodiazepines, ketamine and alfa 2-agonist, etc.

In vasoconstrictor group most commonly epinephrine and phenylephrine are used. Caldwell et al used higher doses of vasoconstrictors, epinephrine $(0.5 \mathrm{mg})$ and phenylephrine ( $5 \mathrm{mg}$ ), and showed that phenylephrine prolonged tetracaine spinal anaesthesia significantly more than epinephrine. But duration of bupivacaine spinal anaesthesia does not appear to be prolonged by phenylephrine. Neostigmine was also tried as an additive, but due to its potential side effect (nausea, vomiting etc.) it is not so commonly used. In vasoconstrictor group most commonly epinephrine and phenylephrine are used. Various Opioid analogues have been used as an additive in intrathecal anaesthesia to improve the onset of action, to prolong the duration of block and to improve the quality of intraoperative and postoperative analgesia.9,10,11 The Shende, D12 et al studied the influence of intrathecal fentanyl on subarachnoid block for Caesarean section and they concluded that adding fentanyl to hyperbaric bupivacaine for spinal anaesthesia markedly improves intra-operative anaesthesia for Caesarean section. Analgesic effects of dexmedetomidine are complex. $\alpha 2$ agonists do have an analgesic effect when injected via the intrathecal or epidural route. The primary site of analgesic action is thought to be the spinal cord. Systemic use of dexmedetomidine shows narcotic sparing. In the postoperative ICU setting, narcotic requirements were reduced by $50 \%$ when patients were receiving a dexmedetomidine drip compared with placebo.

Fentanyl is a partial agonist on $\mu$-opioid receptors and Dexmedetomidine is a $\alpha 2$-agonist. We compared the effects of adding them as an adjunct with Bupivacaine in Spinal Anaesthesia.

\section{METHODS}

After approval from the Ethical Committee of the institution, the present randomized control double bind study was conducted on patients admitted in the SVBP Hospital, affiliated to LLRM Medical College, Meerut. Patients undergoing elective vaginal hysterectomy were included in the study. The sample size was kept 100.This was because the power analysis was done for both the study groups for completion of analgesia and effective period of analgesia. At 95\% confidence the power of test was observed to be 1 for both the parameters for both the groups, thus implying that the chances of alfa-error are negligible with the trends obtained in present study. Our study included 100 patients with ASA Grade I or II of female sex, age ranging between 3565 years, BMI:18.5 to $24.9 \mathrm{Kg} / \mathrm{m}^{2}$, posted for vaginal Hysterectomy.

A thorough pre-anaesthetic check-up was done. Patients were asked about any previous anaesthetic exposure (general or regional anaesthesia) and its outcome. A complete general and systemic examination was done to rule out any cardiovascular, respiratory and neurological or other systemic illness; to assess for any difficulty in airway and to look for any deformity of lumbar spine, any other disease involving spine or any skin infection. Intervertebral space was assessed properly. All the necessary investigations were done like Haemoglobin, Packed cell volume, Total leukocyte count, Differential leukocyte count, Bleeding time, Clotting time, platelet count, blood sugar, blood urea and creatinine in all the patients. Chest X-Ray and Electrocardiogram were prescribed, whenever indicated. Patients were explained about VAS (Visual Analog Scale) scale at the time of preanaesthetic check-up.

Exclusion criteria were patient's refusal for the process, any contraindication to spinal anaesthesia, patients with diseased or deformed spine, or history of trauma to spine. Patients with history of Diabetes, Hypertension or any other severe systemic illness like severe respiratory, cardiovascular and neurological disorder, Patients using alpha-adrenergic receptor antagonist, calcium channel blocker, ACE inhibitor and patients who had history of low back surgery. After taking detailed history and thorough systemic examination and necessary laboratory investigation, Written and informed consent was taken for study. The patient were kept nil orally 8 hours prior to surgery. Preoperative pulse rate, blood pressure, respiratory rate and SPO2 were noted down during pre-anaesthetic check-up, and recorded as baseline value. All patients were explained about the procedure. The patients were pre medicated orally, with tablet Alprazolam $0.25 \mathrm{mg}$ the night before and again at 6 a.m. on the morning of surgery. 


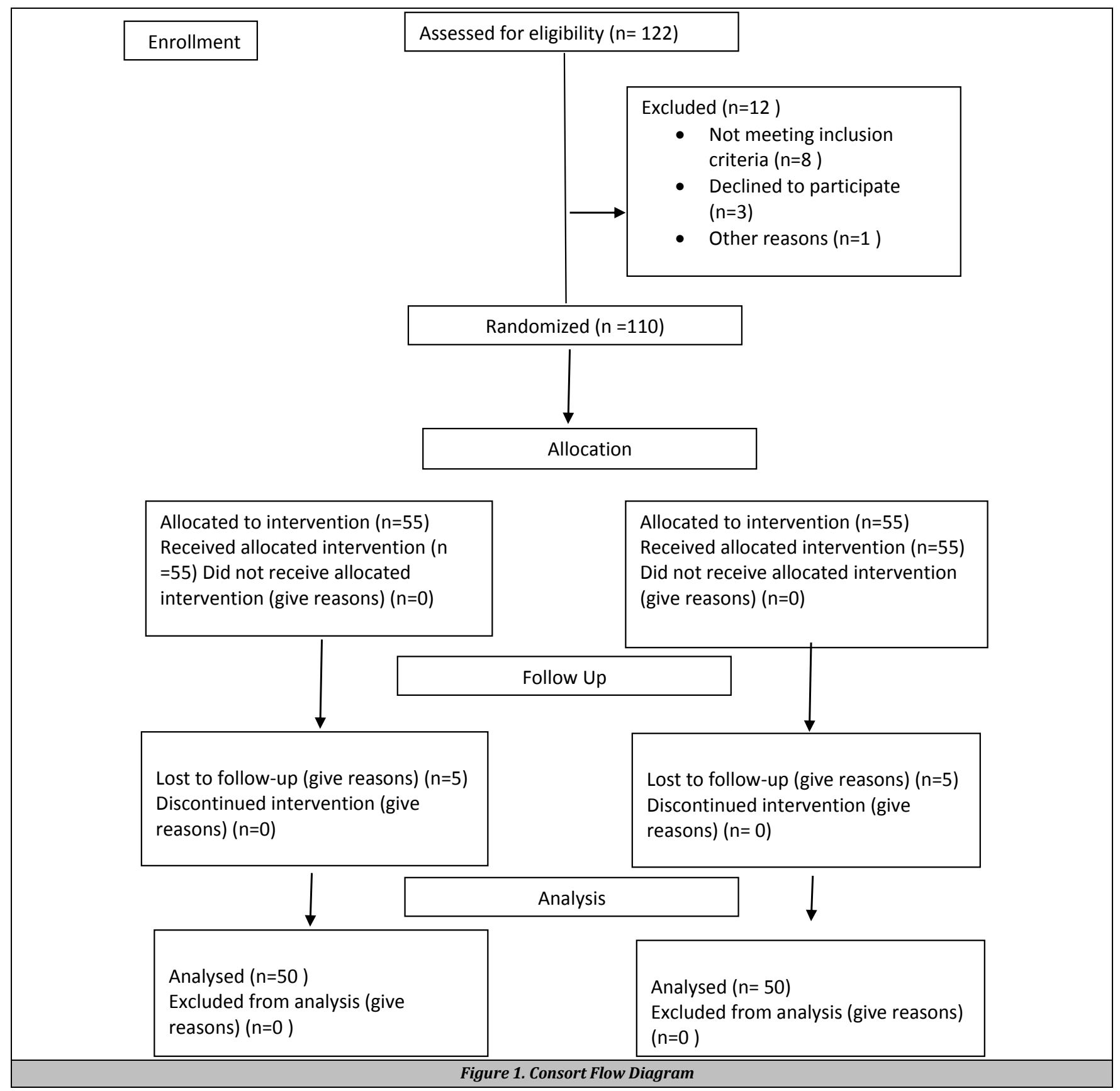

Random distribution of patients to two groups was done by using lottery system. Study was performed by taking 2 groups of 50 patients each, named as Group-I, and Group-II.

\section{Group-I}

(2.5 ml) Hyperbaric Bupivacaine $+(0.5 \mathrm{ml})$ Dexmedetomidine (5 mcg).

\section{Group-II}

$(2.5 \mathrm{ml})$ Hyperbaric Bupivacaine $+(0.5 \mathrm{ml})$ Fentanyl $(25$ $\mathrm{mcg}$ ). Total volume injected intrathecally was $3.0 \mathrm{ml}$.

Preservative free preparation of Dexmedetomidine.

(Dexem; Themist Pharma) is available in $1 \mathrm{ml}$ ampoule containing $100 \mathrm{mcg}(1 \mathrm{ml}, 100 \mathrm{mcg}$ drug diluted in $10 \mathrm{ml}$ syringe i.e. $10 \mathrm{mcg}$ per $\mathrm{ml}$ of which $0.5 \mathrm{ml}, 5 \mathrm{mcg}$ was taken),
Fentanyl (Trofentyl; Troikaa Pharma) is available in $2 \mathrm{ml}$ ampoule containing $50 \mathrm{mcg}$ per $\mathrm{ml}$ fentanyl $(0.5 \mathrm{ml}, 25 \mathrm{mcg}$ was taken). Bupivacaine $0.5 \%$ (heavy) which was used in our study was Anawin heavy (neon pharma).

A total of 122 patients were assessed for eligibility, 8 did not meet inclusion criteria, 3 declined to participate and 1 patient was excluded because of altered investigations. Out of left 110 patients, 10 were lost to follow up. A total of 100 patients of age 35-65 years, American Society of Anesthesiologists physical status I and II of normal Body Mass Index (18.5-24.9 $\left.\mathrm{Kg} / \mathrm{m}^{2}\right)$ undergoing vaginal hysterectomy were included in the study. consort flow diagram.

\section{Blindness of the Study}

Random selection of patients were done by lottery system and preparation of drug was done by one of my helping colleague to maintain the blindness of the study. He handed 
over the prepared drug to us with a unique code of identification on it. We completed all the observations and recordings of the cases without knowing the group of the patient. Only after completion of the study, we came to know the group of the patient with help of the code. This reduced the observer bias.

\section{Anaesthetic Technique}

After shifting the patient to OT, the anaesthetic procedure was explained again. Now the vitals (pulse rate, blood pressure, respiratory rate, $\mathrm{SpO}_{2}$ ) recording was done with multi-parameter monitor and 18 G IV cannula was inserted into a peripheral vein, preferably in left forearm and patient was hydrated with $15 \mathrm{ml} / \mathrm{kg}$ bodyweight Ringer's Lactate solution. The patient was placed in sitting position in a comfortable way either with a stool provided as foot-rest or asking the patient to straighten the leg by extending the knee joint on OT table. The assistant was asked to maintain the patient in a vertical plane while flexing the patient's neck and both the arms are crossed over to open up the lumbar vertebral space. Now by using the index and third finger (palpating finger) we identified the interspinous space. Under full aseptic precautions, part was prepared, painted and draped. At L3-L4 interspinous space, with the help of $25 \mathrm{G}$ Quincke spinal needle spinal anaesthesia was given with the desired drug dose. After giving the drug in subarachnoid space patient was placed in supine position within 1 minutes of intrathecal injection. When the sensory blockade reaches the T10 dermatome, patient was placed in the position appropriate for the surgical procedure.

All the necessary measures e.g. fluid replacement, sedation and continuous monitoring of $\mathrm{SPO} 2$, blood pressure by (noninvasive blood pressure), Electrocardiogram, and Pulse rate were undertaken at appropriate interval.

Pulse Rate Recorded at 5 min interval till 15 min and then at $15 \mathrm{~min}$ intervals till $180 \mathrm{~min}$. If pulse rate $<60 \mathrm{beat} / \mathrm{min}-$ $\mathrm{I} / \mathrm{V}$ atropine $0.5 \mathrm{mg}$ increments was given. Blood Pressure Recorded at $5 \mathrm{~min}$ interval till $15 \mathrm{~min}$ and then at $15 \mathrm{~min}$ intervals till $180 \mathrm{~min}$. Fall of more than $20 \%$ of baseline systolic blood pressure, ephedrine was given in $6 \mathrm{mg}$ increments iv. And fall of more than $30-40 \%$ of baseline systolic blood pressure continuous inotropic support with standard dose of dopamine was started. Respiratory Rate and $\mathrm{SPO}_{2}$ - Recorded at $5 \mathrm{~min}$ interval till $15 \mathrm{~min}$ and then at 15 min till $180 \mathrm{~min}$. If on air $\mathrm{SPO}_{2}<94 \%$ and respiratory movement are normal then intranasal oxygen 3-4 Lit/Min given. If respiratory movement were paradoxical or patient complains of difficulty in breathing and SPO2 was not maintained with above measures respiratory assistance was given with or without endotracheal intubation.

\section{Statistical Analysis}

The statistical analysis was done using SPSS (statistical package for social sciences) Version 15.0 statistical Analysis Software. The values were represented in Number (\%) and Mean \pm SD. The statistical formulae used were mean, standard deviation, chi-square test and student $t$ test. Level of significance: ( $p>0.05$ - Not significant, $p<0.05$-Significant, $p$ $<0.01$-Highly significant, $\mathrm{p}<0.001$ - very highly significant).

\section{RESULTS}

Demographic variables like weight $(\mathrm{P}=0.363)$, age wise distribution $(\mathrm{P}=0.8624)$ of subjects and baseline hemodynamic variables of both the groups were statistically similar. No significant difference among groups was observed $(\mathrm{P}=0.517)$ in mean oxygen saturation. At baseline, the mean oxygen saturation in study group I was $99.70 \pm 0.79 \%$ and $99.48 \pm 1.43 \%$ in study groups II. Showing no statistically significant difference among the two groups $(\mathrm{P}=0.255)$. At all the time intervals the mean oxygen saturation was between 98 to $100 \%$ in all the two groups.

We compared the mean SBP in two groups at different time intervals: At baseline, the mean SBP in group I was $131.88 \pm 9.52 \mathrm{mmHg}$ and in group II was $131.10 \pm 7.91 \mathrm{~mm}$ of Hg. Therefore showing no statistically significant difference among the two groups $(\mathrm{P}=0.829)$. The mean DBP in group I was $84.82 \pm 7.25$ and in group II was $82.88 \pm 6.48 \mathrm{~mm}$ of $\mathrm{Hg}$. Therefore showing no statistically significant difference among the two groups $(\mathrm{P}=0.346)$. A decrease in DBP was observed, A significant difference in mean DBP of different groups was evident from 10 minutes till 105 minutes, however, there was no significant difference among groups at $30 \mathrm{~min}$ and $120 \mathrm{~min}$ time intervals respectively.

At baseline, the mean MAP in study group I was $99.56 \pm 8.66$ and study group II was $98.80 \pm 7.21 \mathrm{~mm}$ of $\mathrm{Hg}$. Therefore showing no statistically significant difference among the two groups $(\mathrm{P}=0.879)$. In study groups I and II, a decrease in MAP was observed. However, there was no significant difference among the groups $(\mathrm{P}=0.277)$. In all the patients sensory blockage up to T6 level was achieved. T5 level was achieved in 33 patients of Study Group I and 32 patients of Study Group II while T4 level was achieved in 23 (46\%) patients of Study Group I and 21 (42\%) patients of Study Group II. The mean time taken to achieve T10 level in study group I was slightly lower $(3.72 \pm 0.50) \mathrm{min}$ as compared to that of Study Group II $(5.76 \pm 0.66) \mathrm{min}$.

In Study Group I and Study Group II, the mean time taken to achieve T6 level of sensory block was significantly lower $(\mathrm{P}<0.001)$. However, no significant difference between two study groups was observed as regards the time taken to achieve sensory blockade up to T5 and T4 levels. As regards, time taken to achieve maximum level of sensory blockade, no significant difference was observed among the study groups $(\mathrm{P}=0.238)$. Up to $1 \mathrm{~min}$ time interval, the median level of motor blockade in all the two groups was 0. Maximum level was achieved in two study groups at 6 minutes interval. The mean time taken to achieve maximum motor block in Study Groups I was $5.76 \pm 0.43 \mathrm{~min}$ and study group II was $5.80 \pm 0.40 \mathrm{~min}$, thus showing a significant intergroup difference $(\mathrm{P}<0.001)$, but no significant difference in none of the subjects in any group.

Pruritis. Hypotension, and sedation were the most common side effect. Bradycardia and respiratory depression were some of the less commonly reported side effects. The study group II subjects had maximum side effects except sedation which was more in study group I. Statistically, no significant intergroup difference were observed for any of the complications $(p>0.05)$. 


\begin{tabular}{|cccccc|}
\hline Variables & $\begin{array}{c}\text { Group 1 } \\
\text { (mean) }\end{array}$ & SD & $\begin{array}{c}\text { Group 2 } \\
\text { (mean) }\end{array}$ & SD & P Value \\
Age (in years) & 40.16 & 9.37 & 40.46 & 9.44 & 0.987 \\
BMI (Kg/m $^{2}$ ) & 20.35 & 1.22 & 19.91 & 1.44 & 0.030 \\
Heart rate (/min.) & 86.44 & 6.50 & 87.62 & 6.42 & 0.664 \\
$\begin{array}{c}\text { Spo2 (\%) } \\
\text { Mean blood pressure } \\
\text { (mm of Hg) }\end{array}$ & 99.70 & 0.79 & 99.48 & 1.43 & 0.255 \\
\hline \multicolumn{7}{|c|}{ Table 1. Demographic Profile of Patients } \\
\hline
\end{tabular}

\begin{tabular}{|c|c|c|c|c|c|c|c|c|c|}
\hline \multirow{2}{*}{$\begin{array}{l}\text { Sl. } \\
\text { No. }\end{array}$} & \multirow{2}{*}{$\begin{array}{c}\text { Time } \\
\text { Interval }\end{array}$} & \multicolumn{3}{|c|}{$\begin{array}{c}\text { Study Group I } \\
(n=50)\end{array}$} & \multicolumn{3}{|c|}{$\begin{array}{c}\text { Study Group II } \\
(n=50)\end{array}$} & \multicolumn{2}{|c|}{ ANOVA } \\
\hline & & n & Mean & SD & n & Mean & SD & "F" & “p” \\
\hline 1 & BL & 50 & 86.44 & 6.50 & 50 & 87.62 & 6.42 & 0.411 & 0.664 \\
\hline 2 & JAS & 50 & 83.08 & 7.04 & 50 & 84.08 & 5.80 & 1.252 & 0.089 \\
\hline 3 & 5 & 50 & 79.62 & 6.87 & 50 & 80.28 & 5.05 & 1.471 & 0.246 \\
\hline 4 & 10 & 50 & 76.60 & 8.50 & 50 & 77.60 & 5.15 & 0.262 & 0.770 \\
\hline 5 & 15 & 50 & 72.52 & 7.68 & 50 & 73.78 & 5.63 & 0.399 & 0.671 \\
\hline 6 & 30 & 50 & 70.38 & 6.82 & 50 & 70.98 & 7.13 & 1.548 & 0.216 \\
\hline 7 & 45 & 50 & 71.26 & 7.74 & 50 & 70.30 & 6.27 & 1.676 & 0.191 \\
\hline 8 & 60 & 50 & 70.84 & 6.96 & 50 & 70.58 & 5.40 & 3.258 & 0.041 \\
\hline 9 & 75 & 48 & 72.04 & 6.67 & 48 & 69.88 & 6.85 & 6.946 & 0.001 \\
\hline 10 & 90 & 39 & 75.44 & 4.57 & 27 & 70.89 & 5.18 & 7.575 & 0.001 \\
\hline 11 & 105 & 6 & 73.50 & 4.46 & 15 & 70.53 & 1.55 & 6.739 & 0.005 \\
\hline 12 & 120 & 5 & 73.60 & 2.97 & 13 & 73.08 & 1.04 & 0.686 & 0.517 \\
\hline
\end{tabular}

\begin{tabular}{|c|c|c|c|c|c|c|c|c|c|}
\hline \multirow{2}{*}{$\begin{array}{l}\text { Sl. } \\
\text { No. }\end{array}$} & \multirow{2}{*}{$\begin{array}{c}\text { Time } \\
\text { Interval }\end{array}$} & \multicolumn{3}{|c|}{$\begin{array}{c}\text { Study Group I } \\
(n=50)\end{array}$} & \multicolumn{3}{|c|}{$\begin{array}{c}\text { Study Group II } \\
(n=50)\end{array}$} & \multicolumn{2}{|c|}{ ANOVA } \\
\hline & & $\mathbf{n}$ & Mean & SD & $\mathbf{n}$ & Mean & SD & “F” & “p” \\
\hline 1. & BL & 50 & 99.70 & 0.79 & 50 & 99.48 & 1.43 & 1.378 & 0.255 \\
\hline 2. & JAS & 50 & 99.48 & 1.13 & 50 & 99.54 & 0.91 & 2.406 & 0.094 \\
\hline 3. & 5 & 50 & 99.22 & 1.36 & 50 & 99.34 & 1.27 & 1.114 & 0.331 \\
\hline 4. & 10 & 50 & 99.10 & 1.02 & 50 & 98.92 & 1.87 & 0.587 & 0.557 \\
\hline 5. & 15 & 50 & 98.90 & 1.23 & 50 & 98.54 & 1.72 & 3.864 & 0.023 \\
\hline 6. & 30 & 50 & 98.94 & 1.10 & 50 & 98.46 & 2.03 & 7.883 & 0.001 \\
\hline 7. & 45 & 50 & 99.04 & 1.43 & 50 & 99.02 & 1.29 & 1.609 & 0.204 \\
\hline 8. & 60 & 50 & 99.14 & 1.80 & 50 & 99.12 & 1.24 & 0.743 & 0.477 \\
\hline 9. & 75 & 48 & 99.10 & 2.11 & 48 & 99.29 & 1.07 & 2.225 & 0.113 \\
\hline 10. & 90 & 39 & 99.62 & 0.71 & 27 & 99.07 & 1.30 & 3.218 & 0.046 \\
\hline 11. & 105 & 6 & 99.83 & 0.41 & 15 & 98.60 & 1.55 & 2.866 & 0.079 \\
\hline 12. & 120 & 5 & 99.80 & 0.45 & 13 & 98.23 & 1.30 & 4.870 & 0.021 \\
\hline
\end{tabular}

\begin{tabular}{|c|c|c|c|c|c|c|c|c|c|}
\hline \multirow{2}{*}{\begin{tabular}{|l} 
Sl. \\
No.
\end{tabular}} & \multirow{2}{*}{ Level } & \multicolumn{3}{|c|}{ Study Group I } & \multicolumn{3}{|c|}{ Study Group II } & \multirow{2}{*}{ “F” } & \multirow{2}{*}{ "p" } \\
\hline & & n & Mean & SD & n & Mean & SD & & \\
\hline 1. & T10 & 50 & 3.72 & 0.50 & 50 & 3.80 & 0.53 & 314.96 & $<0.001$ \\
\hline 2. & T8 & 50 & 5.76 & 0.66 & 50 & 5.76 & 0.66 & 179.77 & $<0.001$ \\
\hline 3. & T6 & 50 & 7.00 & 0.49 & 50 & 7.02 & 0.51 & 162.96 & $<0.001$ \\
\hline 4. & T5 & 33 & 9.61 & 1.09 & 32 & 9.97 & 0.35 & 0.837 & 0.364 \\
\hline 5 & $\mathrm{~T} 4$ & 23 & 11.00 & 2.47 & 21 & 11.39 & 2.86 & 1.016 & 0.319 \\
\hline 6 & $\begin{array}{c}\text { Maximum } \\
\text { level }\end{array}$ & 50 & 10.72 & 2.87 & 50 & 10.58 & 3.07 & 1.448 & 0.238 \\
\hline \multicolumn{10}{|c|}{$\begin{array}{l}\text { Table 4. Mean Time Taken to Achieve } \\
\text { Sensory Blockade at Different Levels }\end{array}$} \\
\hline
\end{tabular}

\begin{tabular}{|c|c|c|c|c|c|c|c|c|c|}
\hline \multirow[t]{2}{*}{$\begin{array}{l}\text { Sl. } \\
\text { No. }\end{array}$} & \multirow[t]{2}{*}{ Time } & \multicolumn{3}{|c|}{$\begin{array}{l}\text { Study Group I } \\
(n=50)\end{array}$} & \multicolumn{3}{|c|}{$\begin{array}{l}\text { Study Group } \\
(n=50)\end{array}$} & \multicolumn{2}{|c|}{$\begin{array}{c}\text { Significance } \\
\text { of difference } \\
\text { (Kruskall } \\
\text { Wallis test) }\end{array}$} \\
\hline & & $P_{50}$ & Min & Max & $P_{50}$ & Min & Max & $\mathbf{z}$ & "p" \\
\hline 1. & $30 \mathrm{~s}$ & 0 & 0 & 0 & 0 & 0 & 0 & & \\
\hline 2. & $1 \mathrm{~min}$ & 0 & 0 & 1 & 0 & 0 & 1 & 33.468 & $<0.001$ \\
\hline 3. & $2 \min$ & 1 & 1 & 1 & 0 & 0 & 1 & 131.65 & $<0.001$ \\
\hline 4. & $3 \mathrm{~min}$ & 1 & 1 & 2 & 1 & 1 & 2 & 35.433 & $<0.001$ \\
\hline 5 & $4 \mathrm{~min}$ & 2 & 2 & 2 & 2 & 2 & 2 & 149.00 & $<0.001$ \\
\hline 6 & $5 \mathrm{~min}$ & 2 & 2 & 3 & 2 & 2 & 3 & 102.60 & $<0.001$ \\
\hline 7 & $6 \mathrm{~min}$ & 3 & 3 & 3 & 3 & 2 & 3 & 143.45 & $<0.001$ \\
\hline 8 & $7 \mathrm{~min}$ & 3 & 3 & 3 & 3 & 3 & 3 & 149.00 & $<0.001$ \\
\hline 9 & $8 \mathrm{~min}$ & 3 & 3 & 3 & 3 & 3 & 3 & 149.00 & $<0.001$ \\
\hline 10 & $9 \mathrm{~min}$ & 3 & 3 & 3 & 3 & 3 & 3 & - & - \\
\hline 11 & $10 \mathrm{~min}$ & 3 & 3 & 3 & 3 & 3 & 3 & - & - \\
\hline 12 & $15 \mathrm{~min}$ & 3 & 3 & 3 & 3 & 3 & 3 & - & - \\
\hline \multicolumn{10}{|c|}{$\begin{array}{c}\text { Table 5. Median Level of Motor Blockade } \\
\text { Achieved at Different Time Intervals }\end{array}$} \\
\hline
\end{tabular}

\section{DISCUSSION}

The mean time to achieve sensory block up to T10 level in study group I was $3.72 \pm 0.50$ minutes and study group II
$3.80 \pm 0.53$ minutes. These showed statistically significant intergroup difference ( $p$ value $<0.001$ ), but no significant difference between study group I and II ( $p$ value $=0.440$ ).

Singh hyang $\mathrm{j}^{7}$ et al used intrathecal fentanyl with bupivacaine to prolong sensory blockade and they concluded that fentanyl prolonged the duration of bupivacaine induced sensory block and reduced the analgesic requirement in the early postoperative period following bupivacaine spinal block.

Shende, $\mathrm{D}^{12}$ et al studied the influence of intrathecal fentanyl on subarachnoid block for Caesarean section and they concluded that adding fentanyl to hyperbaric bupivacaine for spinal anaesthesia markedly improves intraoperative anaesthesia for Caesarean section. ${ }^{13-17}$

Intrathecal dexmedetomidine along with bupivacaine causes significant improvement in the duration of sensory and motor block as well as operative analgesia, compared to intrathecal bupivacaine alone in gynaecological procedure.[18] Another study demonstrated that effect of dexmedetomidine added to spinal bupivacaine for urological procedures, prolonged the duration and quality of analgesia.[19]

We have seen that onset time for Dexmedetomidine or Fentanyl with Bupivacaine was shorter than Bupivacaine alone. The mean time to achieve Grade III motor block in study group I was $5.76 \pm 0.43$ minutes. And study group II was $5.80 \pm 0.40$ minutes.

The mean time to achieve Grade III motor blockade was minimum in study group $\mathrm{I}$, and showing a significant intergroup difference ( $\mathrm{p}$ value $<0.001$ ). There was no significant difference in the meantime to achieve grade III motor blockade between the study group I and study group II ( $p$ value $>0.05$ ) .

Jaishri bogra ${ }^{8}$ et al studied the synergistic effect of intrathecal fentanyl and bupivacaine in spinal anaesthesia for caesarean section and they concluded that fentanyl potentiate and reduce the dose of bupivacaine.20-22 They found the time period for sensory regression to S1 level were $306.0 \pm 13.32,206.14 \pm 16.69$ minutes in, study group I, and II respectively. The time period for regression to Bromage- 0 were $1,257.70 \pm 14.61,178.54 \pm 14.23$ minutes in, study group I, and II respectively.

B N Biswas ${ }^{9}$ et al compared the effects of adding $12.5 \mathrm{mcg}$ Fentanyl to $2.0 \mathrm{ml}$ Bupivacaine and concluded that duration of Effective analgesia was prolonged to 248 minutes in comparison to 150 minutes when Bupivacaine was used alone.

The mean time for duration of analgesia was found to be maximum in study group-I followed by study group-II. The mean duration of analgesia was found to be effective analgesia was found to $373.0 \pm 16.26$ and $302.40 \pm 16.01$ minutes in the study group I and II respectively. It means that the longest duration of analgesia were experienced by the patients receiving Dexmedetomidine, followed by the patients receiving Fentanyl. ${ }^{23}$

There was no statistically significant intergroup difference in pulse rate observed among the two study groups throughout the study period ( $\mathrm{p}$ value $>0.05$ ), except $60,75,90$, and 105 minutes at which There was statistically significant intergroup difference observed among the two study groups $(\mathrm{p}<0.05)$.

At most of the times the mean value in all the two groups remained between 70 to 90 beats per minute. 
There was no statistically significant intergroup difference in SpO2 observed among the two study groups throughout the study period ( $\mathrm{p}$ value $>0.05$ ), except 15,30 and 120 minutes at which there was statistically significant intergroup difference observed among the two study groups ( $p>0.05$ ). Most of the times the mean value of Sp02 in all the two groups remained above 99\%. There was statistically significant intergroup difference observed among the two study groups $(\mathrm{p}>0.05)$. In all the groups as compared to baseline the mean S.B.P. was lower at all-time intervals. ${ }^{24,25}$

In all the two groups, the mean change from baseline was significant statistically from JAS till 105 minutes post JAS. At 120 minutes the mean change from baseline was significant in study group II only. It means that fall in SBP was observed maximum in patients receiving Fentanyl followed by patients receiving Dexmedetomidine. Diastolic Blood Pressure in study Group I mean value ranged from 58.18 \pm 6.32 (at 60 min) to $84.82 \pm 7.25 \mathrm{~mm} \mathrm{Hg}$ (baseline) and in study Group II the mean value ranged from $57.02 \pm 5.48$ (45 $\mathrm{min})$ to 82.88 \pm 6.48 (Baseline) $\mathrm{mm} \mathrm{Hg}$.

There were no statistically significant intergroup difference observed among the three study groups at BL, JAS, and 5 minutes ( $p$ value $>0.05$ ), but statistically significant intergroup differences were observed from $10 \mathrm{~min}$ to 105 min time interval ( $\mathrm{p}$ value $<0.05$ ), except 30 , and 120 minutes. It means that fall in DBP was observed maximum in patients receiving Fentanyl followed by patients receiving Dexmedetomidine. ${ }^{26}$ Mean Arterial Pressure in study group I the mean value ranged from $73.80 \pm 6.53$ (45 $\mathrm{min}$ ) to $95.56 \pm 8.66 \mathrm{~mm} \mathrm{Hg}$ (Baseline) and in study group II the mean value ranged from $73.0 \pm 5.36$ (45 $\mathrm{min}$ ) to $98.80 \pm 7.21 \mathrm{mmHg}$ (baseline).

There was no statistically significant intergroup difference observed among the two study groups at BL and JAS ( $p$ value $>0.05$ ), statistically significant intergroup differences were observed from $5 \mathrm{~min}$ to $105 \mathrm{~min}$ time interval ( $p$ value $<0.05$ ), except 30 , and 120 minutes.

\section{CONCLUSIONS}

By adding Dexmedetomidine 5 mcg single shot spinal blockade with Bupivacaine $12.5 \mathrm{mg}$ not only provides rapid onset, profound analgesia with good relaxation for surgery but also prolongs the duration of sensory and motor blockade and extends the duration of post-operative analgesia without significant side effects. The overall effect and duration is superior to addition of $25 \mathrm{mcg}$ of Fentanyl in comparison to dexmedetomidine.

\section{REFERENCES}

[1] Lawhead RG, Blaxall HS, Bylund BD. Alpha-2A is the predominantalpha 2 - adrenergic receptor subtype in human spinal cord. Anesthesiology 1992;77(5):983-91.

[2] Cushing H. On the avoidance of shock in major amputations by cocainization of large nerve-trunks preliminary to their division. With observations on blood-pressure changes in surgical cases. Ann Surgery 1902;36(3):321-45.

[3] Quincke HI. Die lumbalpunction des hydrocephalus. Berl Klin Wochenschr. British Journal of Anaesthesia 1891;28:929-33.

[4] Bier A. Experiments in cocainization of the spinal cord. Dtsch Z Chir 1899;51:361-9.

[5] Convert CR, Fox GS. Anesthesia for hip surgery in elderly. Canadian J Anaesthesia 1989;36(3 Pt 1):311-9.

[6] Hampl KF, Schneider MC, Pargger H, et al. A similar incidence of transient neurological symptom after spinal anaesthesia with $2 \%$ and 5\% lidocaine. Anaesth Analg 1996;83(5):1051-4.

[7] Singh H, Yang J, Thornton K, et al. Intrathecal fentanyl prolongs sensory bupivacaine spinal block. Can J Anesth 1995;42(11):987-91.

[8] Bogra J, Arora N, Srivastava P. Synergistic effect of intrathecal fentanyl and bupivacaine in spinal anesthesia. Bmc Anesthesiology 2005;5(1):5.

[9] Biswas BN, Rudra A, Bose BK, et al. Intrathecal Fentanyl with hyperbaric bupivacaine improves analgesia during caeserian delivery and in early postoperative period. Indian J Anaesthesia 2002;46(6):469-72.

[10] Kennedy F, Effron AS, Perry G. The grave spinal cord paralysis caused by spinal anesthesia. Surg Gynecol Obstet 1950;91(4):385-98.

[11] Cope RW. The Woolley and Roe case: Woolley and Roe versus Ministry of Health and Others. Anaesthesia 1954;9(4):249-70.

[12] Shende D, Cooper GM, Bowden MI. The influence of intrathecal fentanyl on the characteristics of subarachnoid block for cesarean section. Anesthesia 1998;53(7):706-10.

[13] Mortan AW. The subarachnoid injection of cocaine for operation upon the upper part of the body. JAMA 1928;39:1162.

[14] Koster H. Spinal analgesia with special reference to its use in surgery of the head, neck and thorax. Am J Surg 1928;5:554.

[15] Aho MS, Erkola OA, Scheinin H, et al. Effect of intravenously administered dexmedetomidine on pain after laparoscopic tubal ligation. Anesth Analg 1991;73(2):112-8.

[16] Talke PO, Caldwell JE, Richardson CA, et al. The effect of dexmedetomidine on neuromuscular blockade in human volunteers. Anesth Analg 1999;88(3):633-9.

[17] Venn RM, Bradshaw CJ, Spencer R, et al. Preliminary UK experience of dexmedetomidine, a novel agent for postoperative sedation in the intensive care unit. Anaesthesia 1999;54(12):1136-42.

[18] Al-Ghanem SM, Massad IM, Al-Mustafa MM, et al. Effects of adding dexmeditomedine versus fentanyl to intrathecal bupivacaine on spinal block characteristics in gynecological procedures: a double blind controlled study. American Journal of Applied Sciences 2009;6(5):882-7.

[19] Al-Mustafa MM, Abu-Halaweh SA, Aloweidi AS, et al. Effect of dexmedetomidine added to spinal bupivacaine for urological procedures. Saudi Med Journal 2009;30(3):365-70. 
[20] Martin E, Ramsay G, Mantz J, et al. The role of the 2adrenorecgtor agonist dexmedetomidine in postsurgical sedation in the intensive care unit. J Intensive Care Med 2003;18(1):29-41.

[21] Bouaziz H, Hewitt C, Eisenach JC. Subarachnoid neostigmine potentiation of alpha 2-adrenergic agonist analgesia. Dexmedetomidine versus clonidine. Reg Anesth 1995;20(2):121-7.

[22] Kanazi GE, Aouad MT, Jabbour-Khoury SI, et al. Effect of low-dose dexmedetomidine or clonidine on the characteristicss of bupivacaine spinal block. Acta Anesthesiol Scand 2006;50(2):222-7.
[23] Eisenach JC, De Kock M, Klimscha W. Alpha 2-adrenergic agonists for regional anesthesia. A clinical review of clonidine (1984-1995). Anesthesiology 1996;85(3):65574.

[24] Scheinin H, Aantaa R, Anttila M, et al. Reversal of the sedative and sympatholytic effects of dexmedetomidine with a specific alpha 2-adrenoreceptor antagonist atipamezole: a pharmacodynamic and kinetic study in healthy volunteers. Anesthesiology 1998;89(3):574-84.

[25] Memis D, Turan A, Karamanlioglu B, et al. Adding dexmedetomidine to lodocain for intravenous regional anesthesia. Anesth Analg 2004;98(3):835-40.

[26] Hutter CD. The Woolley and Roe case: a reassessment. Anaesthesia1990;45(10):859-64. 